CAPSULE COMMENTARIES

\title{
Capsule Commentary on Yeh, et al., Depressed Mood, Perceived Health Competence and Health Behaviors: a Cross-Sectional Mediation Study in Outpatients with Coronary Heart Disease
}

\author{
Michael J. Roy, MD MPH \\ Department of Medicine, Uniformed Services University of the Health Sciences, Bethesda, MD, USA.
}

$\mathrm{J}$ Gen Intern Med 34(7):1289

DOI: $10.1007 / \mathrm{s} 11606-019-04917-8$

(c) Society of General Internal Medicine 2019

$\mathrm{C}$ oronary heart disease (CHD) is the most common cause of death, and depression is one of the most common causes of morbidity, in developed nations. ${ }^{1}$ The relationship between depression and CHD is a two-way street, with each adversely impacting the prognosis of the other. While we still have an insufficient understanding of the underlying mechanisms involved in this relationship, worse health behaviors, including diet, exercise, and tobacco and alcohol use patterns, represent highly significant factors. Yeh et al. provide a valuable contribution to the literature in their identification of perceived health competence as a significant mediator. ${ }^{2}$ They estimate that perceived health competence is responsible for about one-quarter of the total effect of depressed mood on health behaviors. Essentially, they are suggesting that those who are depressed are less likely to feel that it is within their power to change their behavior in such a manner to impact their health, and thus do not follow through on quitting smoking or improving their diet or exercise regimen.

The identified relationship has face validity. However, there are some significant limitations to this study, which the authors appropriately acknowledge. Arguably, the most salient of these is that an unmeasured factor such as pessimism, or hopelessness, might be significantly related to depression, perceived health competence, and health behaviors, and is in fact the key to the relationship between these factors. Beck and Weissman previously developed a Hopelessness $\mathrm{Scale}^{3}$ to measure pessimism, which might be worth incorporating in future studies of this relationship.

Published online April 22, 2019
The ultimate goal in future research would be to translate this work into interventions that reduce cardiac events and overall mortality. One might hope that treating depression alone would engender improvements in health behaviors as well as consequent cardiac outcomes, but as Yeh et al. document in their discussion, such intervention has had little impact on the former, and results have been mixed with regard to the latter. Perhaps a dual intervention, targeting both depression and perceived health competence, can enable depressed patients to escape this heart of darkness.

Corresponding Author: Michael J. Roy, MD MPH; Department of Medicine, Uniformed Services University of the Health Sciences, Bethesda, MD, USA (e-mail: Michael.roy@usuhs.edu).

\section{Compliance with Ethical Standards:}

The opinions expressed are solely those of the author and are not to be construed as representing Uniformed Services University, the Department of Defense, or the U.S. government.

Conflict of Interest: The author has no conflicts of interest to report, financial or otherwise.

\section{REFERENCES}

1. World Health Organization. The Top Ten Causes of Death. https://www. who.int/news-room/fact-sheets/detail/the-top-10-causes-of-death.

2. Yeh VM, Mayberry LS, Bachmann JM, Wallston, KA, Roumie C, Muñoz D, Kripalani S. Depressed mood, perceived health competence and health behaviors: a cross-sectional mediation study in outpatients with coronary heart disease. JGIM. 2018. https://doi.org/10.1007/s11606-018-4767-1.

3. Beck AT, Weissman A. The measurement of pessimism: the hopelessness scale. J Consulting Clin Psychol. 1974;42:861-865.

Publisher's Note: Springer Nature remains neutral with regard to jurisdictional claims in published maps and institutional affiliations. 